\title{
Should concurrent prophylactic cholecystectomy be performed in laparoscopic sleeve gastrectomy?
}

Birkan BiRBEN', Gökhan AKKURT'1', Mesut TEZ², Barış Doğu YILDIZ'

${ }^{1}$ Ankara City Hospital, Department of General Surgery, Ankara, Turkey

${ }^{2}$ SBU Ankara Research and Training Hospital, Department of General Surgery, Ankara, Turkey

Correspondence

Gökhan AKKURT

Ankara Şehir Hastanesi, Genel Cerrahi Bölümü, Ankara, Türkiye

e-mail:drakkurt06@gmail.com

\section{ABSTRACT}

The causes of gallstone formation include rapid gain or loss of weight. Not all gallstones become symptomatic. Concurrent cholecystectomy in sleeve gastrectomy remains controversial. This study aimed to investigate whether concurrent cholecystectomy should be performed after sleeve gastrectomy (SG).

A total of 268 patients with normal preoperative gallbladder ultrasonography findings, who underwent laparoscopic SG in Ankara Numune Training and Research Hospital between 2011 and 2018, were retrospectively examined. The data collected from 40 patients with symptomatic cholelithiasis during the postoperative follow-up were analyzed.

Forty patients [32(80\%) female and $8(20 \%)$ male] developed symptomatic cholelithiasis after an average of $10.65 \pm 5.98$ months of SG and underwent surgery. The mean age of the patients was $38 \pm 11$ years. The mean body mass index before SG was $48.15 \pm 5.61$. The mean percentage of excess weight loss was $69.85 \pm 17.4$ at the time the patients underwent cholecystectomy. As the percentage of excess weight loss increased, the time to the development of postoperative symptomatic cholelithiasis decreased, and this relationship was statistically significant $(R=0.435, P=0.005)$.

Prophylactic cholecystectomy need not be performed concurrently with SG in patients without preoperative symptomatic gallstones. The reason is that laparoscopic cholecystectomy can be safely performed in the postbariatric surgery period, and the risk of symptomatic gallstone formation depends on individual risk factors.

Key words: Cholelithiasis, laparoscopic sleeve gastrectomy, prophylactic cholecystectomy

\section{INTRODUCTION}

In Turkey, the prevalence of gallbladder stones in the normal population was reported to be $7.5 \%$ in the last two decades [1]. Previous studies showed that the prevalence of these stones in obese patients increases to $21 \%$ [2]. Rapid weight gain and certain conditions causing rapid weight loss, such as bariatric surgery, are among the risk factors for gallbladder stone formation [3]. Concurrent prophylactic cholecystectomy in sleeve gastrectomy (SG) remains controversial. This study aimed to investigate whether concurrent prophylactic cholecystectomy should be performed after SG.

\section{MATERIAL AND METHODS}

\section{Patient data}

After obtaining approval from the ethics com- mittee of the Ankara Numune Training and Research Hospital (approval number: E-19-2576), patients who underwent laparoscopic sleeve gastrectomy (LSG) at the same hospital between 2011 and 2018 were retrospectively analyzed. The patients with gallbladder stones, polyps, or gallbladder sludge on preoperative ultrasonography and those without preoperative images were excluded from the study. A total of 268 patients with normal preoperative gallbladder ultrasonography findings were included in this study. Of these patients, 40 with symptomatic cholelithiasis were evaluated in terms of demographic characteristics, preoperative body mass index (BMI), percentage of excess weight loss (EWL), symptoms, time between two operations, complications associated with cholelithiasis, operation type, and comorbidities. 


\section{Statistical analysis}

The Statistical Package for the Social Sciences (SPSS) 15.0 (SPSS Inc., IL, USA) statistics software was used for statistical analysis. The Fisher exact test was used to compare nominal values because of the nonparametric distribution pattern among the groups. The Mann-Whitney $\mathrm{U}$ test was used to compare the numerical values. The correlation between parameters was calculated using the Pearson correlation test. A P value less than 0.05 was considered statistically significant.

\section{RESULTS}

Symptomatic cholelithiasis developed in 40 [32 (80\%) female and 8 (20\%) male] of the 268 patients with normal preoperative gallbladder ultrasonography findings after an average of $10.65 \pm 5.98$ months of SG. These patients underwent surgery. The analysis of these patients is given in Table 1. The mean age was $38 \pm 11$ years. The mean BMI before SG was 48.15 \pm 5.61 . At the time of cholecystectomy, the mean EWL percentage was $69.85 \pm 17.14$. Acute cholecys- titis developed in one patient (2.5\%), and acute cholecystitis, pancreatitis, and choledocholithiasis complications in another patient (2.5\%) who underwent endoscopic retrograde cholangiopancreatography (ERCP). The operation was completed laparoscopically in 38 (95\%) patients. One patient $(2.5 \%)$ refused surgery. In another patient (2.5\%), laparoscopy was converted into open surgery. This was the same patient who underwent ERCP due to complications. Diabetes mellitus (DM) was present in 10 patients (25\%). The relationship between the presence of DM and the time to the development of symptomatic cholelithiasis after SG was not statistically significant $(P=0.104)$. As the percentage of EWL increased, the time to the postoperative development of symptomatic cholelithiasis decreased, and this relationship was statistically significant ( $R=0.435$ and $P=0.005$ ). However, the relationship between BMI before SG and the time to the postoperative development of symptomatic cholelithiasis was not statistically significant $(R=-0.028, P=0.863)$.

Table 1 Analysis of the patients who developed symptomatic cholelithiasis in the postoperative period

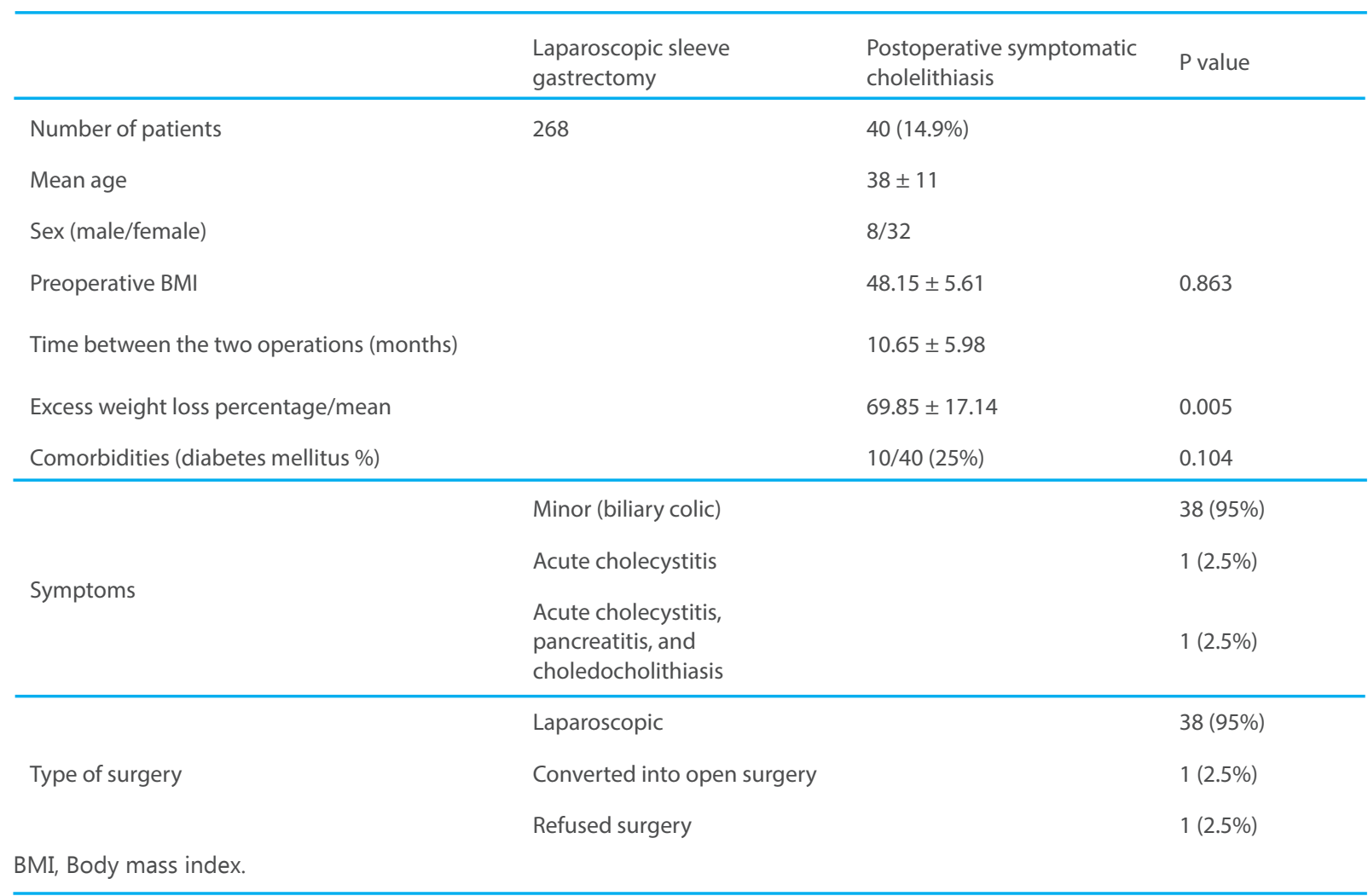




\section{DISCUSSION}

Although prophylactic cholecystectomy is not performed by most bariatric surgeons, it remains an issue that needs to be clarified. The present study was valuable in terms of its contributions to the literature. In this study, symptomatic cholelithiasis developed in $14.9 \%$ of patients after an average of $10.65 \pm 5.98$ months of SG. Manatsathit et al. reported that cholelithiasis occurred in $95.8 \%$ of the patients within the first 18 months after SG, and $22.9 \%$ of these cases had symptomatic cholelithiasis [4]. In a similar study, Coupaye et al. found that after LSG, $12 \%$ of the patients developed symptomatic cholelithiasis, most in the first postoperative year [5]. In another study, Li et al. observed that symptomatic cholelithiasis developed in $5.7 \%$ of the patients after LSG, and routine prophylactic cholecystectomy was not recommended [6]. Altieri et al. reported the rate of cholecystectomy as $10.1 \%$ after SG. It was noted that common bile duct injuries occurred at a high rate $(0.12 \%)$ in patients who underwent cholecystectomy after bariatric surgery. Previous studies suggested that the risks and benefits of prophylactic cholecystectomy should be considered during surgical decision-making [7].

In this study, no statistical relationship existed between the presence of DM and the time to the development of symptomatic cholelithiasis after LSG. In contrast, Manatsathit et al. found that the prevalence of DM in the postoperative cholelithiasis group was significantly lower [4]. In the present study, the relationship between preoperative $\mathrm{BMI}$ and the time to postoperative symptomatic cholelithiasis was not statistically significant. Similarly, Coupaye et al. found that preoperative $\mathrm{BMI}$ and preoperative body weight were not associated with the development of cholelithiasis after LSG [5].

The time to the development of symptomatic cholelithiasis after LSG was found to decrease as EWL increased. Manatsathit et al. also reported that none of the parameters of postoperative body weight, BMI, EWL, and amount and percentage of body weight loss was associated with postoperative stone formation [4]. In a similar study, Coupaye et al. stated that a decrease in the total body weight of more than 30 $\mathrm{kg}$ in the first 6 months after LSG was a risk factor for cholelithiasis [5].
Tustumi et al. determined that the risk of complications was higher in postbariatric laparoscopic cholecystectomies than in cholecystectomy undertaken concurrently with bariatric surgery [8]. Juo et al. found no difference between cholecystectomies performed concurrently with bariatric surgery and after bariatric surgery in terms of specific complications associated with cholecystectomy. Therefore, the need for prophylactic cholecystectomy should be evaluated considering individual risk factors [9]. In this study, conversion from laparoscopic into open surgery was required in only one patient with symptomatic cholelithiasis, while the remaining $97.5 \%$ of the patients underwent LSG. No complications were found in any of the patients.

Although the prevalence of regional cholelithiasis in Turkey was reported to be around $7.5 \%$ in the last two decades, this rate was considered to be even higher due to the limited number of prevalence studies and increasing obesity throughout the country. Therefore, the rate of symptomatic cholelithiasis occurrence after LSG (14.9\%) was not much higher than the real prevalence of this condition in the normal population in Turkey as observed in this study.

This study had a limitation. The number of patients with cholelithiasis in this cohort was low. The prevalence of cholelithiasis should be investigated in a larger cohort of patients with SG.

\section{CONCLUSIONS}

In conclusion, prophylactic cholecystectomy need not be performed concurrently with SG in patients without preoperative symptomatic gallstones. The reason is that laparoscopic cholecystectomy can be safely performed in the postbariatric surgery period, and the risk of symptomatic gallstone formation depends on individual risk factors.

\section{REFERENCES}

1. Yıldırım B., et al., Tokat ili erişkinleri'nde kolelitiazis sıklığı ve olası risk faktörleri. Akademik Gastroenteroloji Dergisi. 2008; 7(2):83-86.

2. Mishra, T., K.K. Lakshmi, and K.K. Peddi, Prevalence of cholelithiasis and choledocholithiasis in morbidly obese south Indian patients and the further development of biliary calculus disease after sleeve gastrectomy, gastric bypass and mini gastric bypass. Obesity surgery. 2016; 26(10):2411-2417.

3. Bora, G., B.Ç. Sonbahar, and V. Genç, Bariatric surgery and gallstone problems. JSM Gastroenterol Hepatol. 2017; 5:10781082. 
4. Manatsathit, W., et al., The incidence of cholelithiasis after sleeve gastrectomy and its association with weight loss: A two-centre retrospective cohort study. International Journal of Surgery. 2016; 30:13-18.

5. Coupaye, M., et al., Comparison of the incidence of cholelithiasis after sleeve gastrectomy and Roux-en-Y gastric bypass in obese patients: a prospective study. Surgery for Obesity and Related Diseases. 2015; 11(4):779-784.

6. Li, V.K.M., et al., Symptomatic gallstones after sleeve gastrectomy. Surgical endoscopy. 2009; 23(11):2488.
7. Altieri, M.S., et al., Incidence of cholecystectomy after bariatric surgery. Surgery for Obesity and Related Diseases. 2018; 14(7):992-996.

8. Tustumi, F., et al., Cholecystectomy in patients submitted to bariatric procedure: a systematic review and meta-analysis. Obesity surgery. 2018; 28(10):3312-3320.

9. Juo, Y.-Y., et al., Cost analysis and risk factors for interval cholecystectomy after bariatric surgery: a national study. Surgery for Obesity and Related Diseases. 2018; 14(3):368-374. 